\title{
Risk factors for febrile neutropenia in patients receiving docetaxel chemotherapy for castration-resistant prostate cancer
}

\author{
Masaki Shiota • Akira Yokomizo • Ario Takeuchi • Keijiro Kiyoshima • \\ Junichi Inokuchi • Katsunori Tatsugami • Seiji Naito
}

Received: 23 November 2013 / Accepted: 16 June 2014 / Published online: 5 July 2014

(C) Springer-Verlag Berlin Heidelberg 2014

\begin{abstract}
Purpose Docetaxel is a standard therapy for patients with castration-resistant prostate cancer (CRPC). However, docetaxel-associated adverse events (AEs) such as febrile neutropenia (FN) can impair quality of life and may become life-threatening. In this study, we clarified the AEs and risk factors associated with FN in clinical settings.

Methods This study included 37 Japanese patients with CRPC who were treated with $70-75 \mathrm{mg} / \mathrm{m}^{2}$ docetaxel and $10 \mathrm{mg}$ prednisone every 3 or 4 weeks between 2008 and 2012 . AEs, risk factors for FN, and the prognostic significance of several clinicopathological factors were analyzed.

Results Hematological AEs of $\geq$ grade 3 included neutrocytopenia in 36 patients $(97.3 \%)$, leukopenia in 24 patients $(64.9 \%)$, lymphopenia in 10 patients $(27.0 \%)$, and FN in 4 patients $(10.8 \%)$. In addition, severe nonhematological AEs included colonic perforation, interstitial pneumonia, and acute respiratory distress syndrome in 1 patient each. Severe lymphopenia was positively associated with the incidence of FN. Low serum albumin and low lymphocyte count were identified as possible pre-treatment risk factors, while severe lymphopenia was identified as a post-treatment risk factor.

Conclusions Non-hematological AEs as well as substantial hematological AEs were recognized in the Japanese population treated with docetaxel chemotherapy against CRPC. Preand post-treatment lymphopenia and pre-treatment serum
\end{abstract}

Electronic supplementary material The online version of this article (doi:10.1007/s00520-014-2328-7) contains supplementary material, which is available to authorized users.

M. Shiota $\cdot$ A. Yokomizo $(\triangle) \cdot$ A. Takeuchi $\cdot$ K. Kiyoshima

$\mathrm{J}$. Inokuchi $\cdot \mathrm{K}$. Tatsugami $\cdot \mathrm{S}$. Naito

Department of Urology Graduate School of Medical Sciences,

Kyushu University, 3-1-1 Maidashi, Higashi-ku,

Fukuoka 812-8582, Japan

e-mail: yokoa@uro.med.kyushu-u.ac.jp albumin should be considered in order to minimize the risk of FN when selecting patients with prostate cancer for docetaxel therapy, and when considering dose modifications, and the prophylactic use of granulocyte colony-stimulating factor.

Keywords Castration-resistant prostate cancer - Docetaxel · Lymphopenia $\cdot$ Febrile neutropenia $\cdot$ Risk factor

\section{Introduction}

Prostate cancer is the most common non-cutaneous cancer and one of the leading causes of cancer-related mortality in men in developed countries. Since Hugging et al. revealed that castration and estrogen suppressed prostate cancer growth [1], androgen-deprivation therapy has been a major therapy for recurrent or advanced prostate cancer [2, 3]. However, although most prostate cancers initially require androgens for their growth and survival and are therefore inhibited by androgen-deprivation therapy, they subsequently develop the ability to regrow and progress even during androgendeprivation therapy and are then defined as castrationresistant prostate cancer (CRPC) [4, 5]. Prior to 2004, no significant therapies existed to prolong survival in patients with CRPC, but the natural taxane from Taxus baccata, docetaxel, together with prednisone, has since shown a significant survival benefit among patients with CRPC [6, 7]. In addition, the novel synthetic taxane cabazitaxel, together with prednisone, has also recently been shown to prolong overall survival (OS) in CRPC patients after docetaxel treatment [8]. Thus, taxanes, including docetaxel and cabazitaxel, are currently the standard chemotherapeutic agents conferring survival benefit in patients with CRPC. However, several novel therapeutic agents targeting the androgen axis have recently been developed, including abiraterone acetate and enzalutamide as well as the immunotherapeutic agent sipuleucel-T [9-12]. 
Unfortunately, many chemotherapeutic agents, including taxanes, can cause severe and potentially life-threatening adverse events (AEs), compared with hormonal and immune therapies. Accordingly, doctors are faced with choosing between a taxane and hormonal therapy (abiraterone acetate and enzalutamide) as first-line treatment for patients with CRPC [13]. Because AEs are a critical factor in selecting the appropriate therapy for each patient, it is vital to understand the risk factors in individual patients.

Febrile neutropenia (FN) predisposes patients to serious infections, resulting in high economic and labor costs, reduced quality of life, and even treatment-related death [14-16]. Previous studies found $\mathrm{FN}$-associated death rates among inhospital patients of $6.8-9.5 \%[14,16]$. FN is therefore a major concern during chemotherapy. The risk of FN after chemotherapy depends on the type and dose of anti-cancer drug. FN risk has been classified as follows: high risk $>20 \%$, intermediate risk $20-10 \%$, and low risk $<10 \%$ [17]. However, FN risk also depends on individual risk factors for each patient, such as age, performance status (PS), coexisting infections, disease stage or underlying immunosuppression represented by decreased immunological cell count, and comorbidities such as diabetes mellitus [18]. An incidence of FN of $3 \%$ was reported in a phase III study of Western men treated with docetaxel for CRPC [6], compared with the higher rate $16.3 \%$ in a phase II study in Japanese men [19]. These results suggest that docetaxel chemotherapy is a low- or intermediate-risk factor for $\mathrm{FN}$, and its prophylaxis requires careful consideration, especially among high-risk and Japanese patients. The identification of simple and readily available clinical and biological risk factors for $\mathrm{FN}$ is therefore important for the selection of suitable candidates for docetaxel chemotherapy, as well as when considering dose modifications and FN prophylaxis, such as the prophylactic use of granulocyte colony-stimulating factor (G-CSF) [20].

To address this issue, we investigated the incidence of severe AEs, including FN, during docetaxel chemotherapy against CRPC, and assessed the pre- and posttreatment risk factors for $\mathrm{FN}$ and their relevance in docetaxel chemotherapy.

\section{Patients and methods}

CRPC patients treated with docetaxel chemotherapy at Kyushu University Hospital (Fukuoka, Japan) from 2008 to 2012 were enrolled. This study was approved by the institutional review boards. The eligibility criteria included histopathologically diagnosed adenocarcinoma of the prostate, confirmed failure of prior hormonal therapy, and PS $\leq 2$, determined according to the criteria of the Eastern Cooperative Oncology Group. Progressive disease was defined as an increase of $>2 \mathrm{ng} / \mathrm{ml}$ and a $25 \%$ increase over the nadir in serum values of prostate-specific antigen (PSA), and/or the appearance of a new lesion or progression of one or more known lesions, classified according to the Response Evaluation Criteria in Solid Tumors (RECIST), in patients with measurable disease. Radiographic progression was defined as the progression of measurable disease or bone scan progression [21]. The exclusion criteria included major cardiovascular, liver, or renal diseases, and/or other severe comorbidities.

Docetaxel was given according to a 3- or 4-weekly $\left(70-75 \mathrm{mg} / \mathrm{m}^{2}\right.$ ) regimen based on the schedule reported by the TAX 327 study [6]. Prednisone $5 \mathrm{mg}$ was generally administered twice daily, simultaneously with hormonal therapy. The docetaxel dose and schedule were modified according to the severities of AEs in each case. If the neutrophil count fell below $500 / \mathrm{mm}^{3}$ or $1,000 / \mathrm{mm}^{3}$ in the presence of a fever of over $38^{\circ} \mathrm{C}$, G-CSF was administered until the recovery of neutrophil count according to the medical treatment indication covered by the health insurance in Japan, though prophylactic antibiotics were not administered. Treatment with docetaxel was continued based on the physician's judgment, taking into consideration disease progression and AEs, or until patient refusal. AEs caused by docetaxel were grouped according to the Common Terminology Criteria for Adverse Events (CTCAE) v4.0 grading system [22], and AEs of severe grade 3 or above were recorded. Pre-treatment laboratory data were obtained within 1 month before initiation of the first chemotherapy administration.

All statistical analyses were performed using JMP9 software (SAS Institute, Cary, NC, USA). The correlations between clinicopathological parameters and the incidences of severe lymphopenia and chemotherapy-induced FN were examined by $\chi^{2}$ or Student's $t$ tests. $P$ values $<0.05$ were considered significant.

\section{Results}

This study included a total of 37 Japanese men with CRPC who were observed for a median of 14.4 months (2.342.7 months). Several types of severe AEs were recorded, as shown in Table 1 . The most common $\geq$ grade 3 hematological AE was neutrocytopenia in 36 patients $(97.3 \%)$, followed by leukopenia in 24 patients $(64.9 \%)$ and lymphopenia in 10 patients $(27.0 \%)$. Other hematological AEs included grade 3 anemia in 2 patients $(5.4 \%)$ and grade 3 thrombocytopenia in 3 patients $(8.1 \%)$. FN was noted in 4 patients $(10.8 \%)$, all which were grade 3 . In addition to the hematological AEs, several non-hematological severe AEs were recognized, including 1 patient with colonic perforation needing surgical repair, 1 patient with interstitial pneumonia leading to 
Table 1 Treatment-related adverse events of grade 3 or over

\begin{tabular}{lllll}
\hline Event, patients (\%) & Grade $\geq 3$ & Grade 3 & Grade 4 & Grade 5 \\
\hline Hematological & & & & \\
$\quad$ Leukopenia & $24(64.9)$ & $16(43.2)$ & $8(21.6)$ & \\
$\quad$ Neutropenia & $36(97.3)$ & $14(37.8)$ & $22(59.5)$ & - \\
Febrile neutropenia & $4(10.8)$ & $4(10.8)$ & - & - \\
Lymphopenia & $10(27.0)$ & $9(24.3)$ & $1(2.7)$ & \\
Anemia & $2(5.4)$ & $2(5.4)$ & - & - \\
Thrombocytopenia & $3(8.1)$ & $2(5.4)$ & $1(2.7)$ & - \\
Non-hematological & & & & - \\
Diarrhea & $2(5.4)$ & $2(5.4)$ & - & - \\
Colonic perforation & $1(2.7)$ & - & - & - \\
Acute respiratory distress syndrome & $1(2.7)$ & - & - & - \\
Interstitial pneumonia & $1(2.7)$ & $1(2.7)$ & - & - \\
Hyponatremia & $1(2.7)$ & $1(2.7)$ & - & - \\
\hline
\end{tabular}

cessation of docetaxel chemotherapy, and 1 patient with acute respiratory distress syndrome, which proved fatal, despite intensive care. Grade 3 diarrhea was recorded in 2 patients and grade 3 hyponatremia in 1 patient.

The interactions between FN and other hematological AEs were investigated to delineate the risk factors for FN. As shown in Table 2, severe post-treatment lymphopenia was positively associated with the incidence of FN; 3 out of 10 patients with lymphopenia developed FN (30.0\%), compared with only 1 out of 27 patients without severe lymphopenia (3.7\%). In contrast, severe neutropenia was inversely associated with the incidence of FN; 1 out of 22 patients with severe neutropenia

Table 2 Association between post-treatment blood cytopenia and febrile neutropenia

\begin{tabular}{|c|c|c|c|c|}
\hline Outcome & $\mathrm{FN}$ & Odds ratio & $95 \%$ & $P$ value \\
\hline \multicolumn{5}{|c|}{ Leukopenia } \\
\hline$<\mathrm{G} 4$ & $3 / 29(10.3 \%)$ & 1 & & \\
\hline$\geq \mathrm{G} 4$ & $1 / 8(12.5 \%)$ & 1.24 & $0.11-13.82$ & 0.86 \\
\hline \multicolumn{5}{|c|}{ Neutropenia } \\
\hline$<\mathrm{G} 4$ & $3 / 15(20.0 \%)$ & 1 & & \\
\hline$\geq \mathrm{G} 4$ & $1 / 22(4.5 \%)$ & 0.19 & $0.018-2.04$ & 0.14 \\
\hline \multicolumn{5}{|c|}{ Lymphopenia } \\
\hline$<\mathrm{G} 3$ & $1 / 27(3.7 \%)$ & 1 & & \\
\hline$\geq \mathrm{G} 3$ & $3 / 10(30.0 \%)$ & 11.14 & $1.00-124.33$ & $0.022 *$ \\
\hline \multicolumn{5}{|l|}{ Anemia } \\
\hline$<\mathrm{G} 3$ & 4/35 (11.4\%) & 1 & & \\
\hline$\geq \mathrm{G} 3$ & $0 / 2(0.0 \%)$ & 0 & - & 0.61 \\
\hline \multicolumn{5}{|c|}{ Thrombocytopenia } \\
\hline$<\mathrm{G} 3$ & 4/34 (11.8 \%) & 1 & & \\
\hline$\geq \mathrm{G} 3$ & $0 / 3(0.0 \%)$ & 0 & - & 0.52 \\
\hline
\end{tabular}

$G$ grade

*Statistically significant developed FN (4.5\%), compared with 3 out of 15 patients without severe neutropenia (20.0\%), though the difference was not significant. Leukopenia, anemia, and thrombocytopenia were not associated with FN.

Furthermore, to identify pre-treatment risk factors for FN, we also investigated the relationships between clinicopathological parameters and post-treatment lymphopenia in addition to FN. As shown in Table 3, low serum albumin $(P=$ $0.018)$ and low lymphocyte count pre-treatment $(P=0.027)$ were associated with severe lymphopenia, though other parameters such as age, PS, comorbidities, and disease progression were not correlated. In contrast, no clinicopathological parameters were significantly directly associated with FN, though pre-treatment serum albumin $(P=0.31)$ and lymphocyte count $(P=0.11)$ tended to be associated with increased risk of FN. Receiver-operator characteristic curves indicated that baseline lymphocyte count and serum albumin were useful indicators for the diagnoses of severe lymphopenia (area under the curve $(\mathrm{AUC})=0.75$, Fig. 1a; and $\mathrm{AUC}=0.84$, Fig. 1b) and $\mathrm{FN}(\mathrm{AUC}=0.70$, Fig. 1c; and $\mathrm{AUC}=0.78$, Fig. 1d), respectively.

Serum albumin and neutrophil/lymphocyte ratio were independent prognostic parameters of OS in univariate analysis (Supplementary table 1), suggesting that both these parameters may help to determine the suitability of patients for docetaxel chemotherapy. The neutrophil/lymphocyte ratio was a significant prognostic factor even after adjustment by Armstrong's risk stratification, which is a standard prognostic model used for docetaxel chemotherapy against prostate cancer [23]. Thrombocytopenia was also significantly correlated with poorer OS, after adjustment by Armstrong's risk stratification, which may suggest that rather than directly predicting poor OS, thrombocytopenia may be associated with poor prognosis as a result of severe systemic inflammation, such as disseminated intravascular coagulation. 


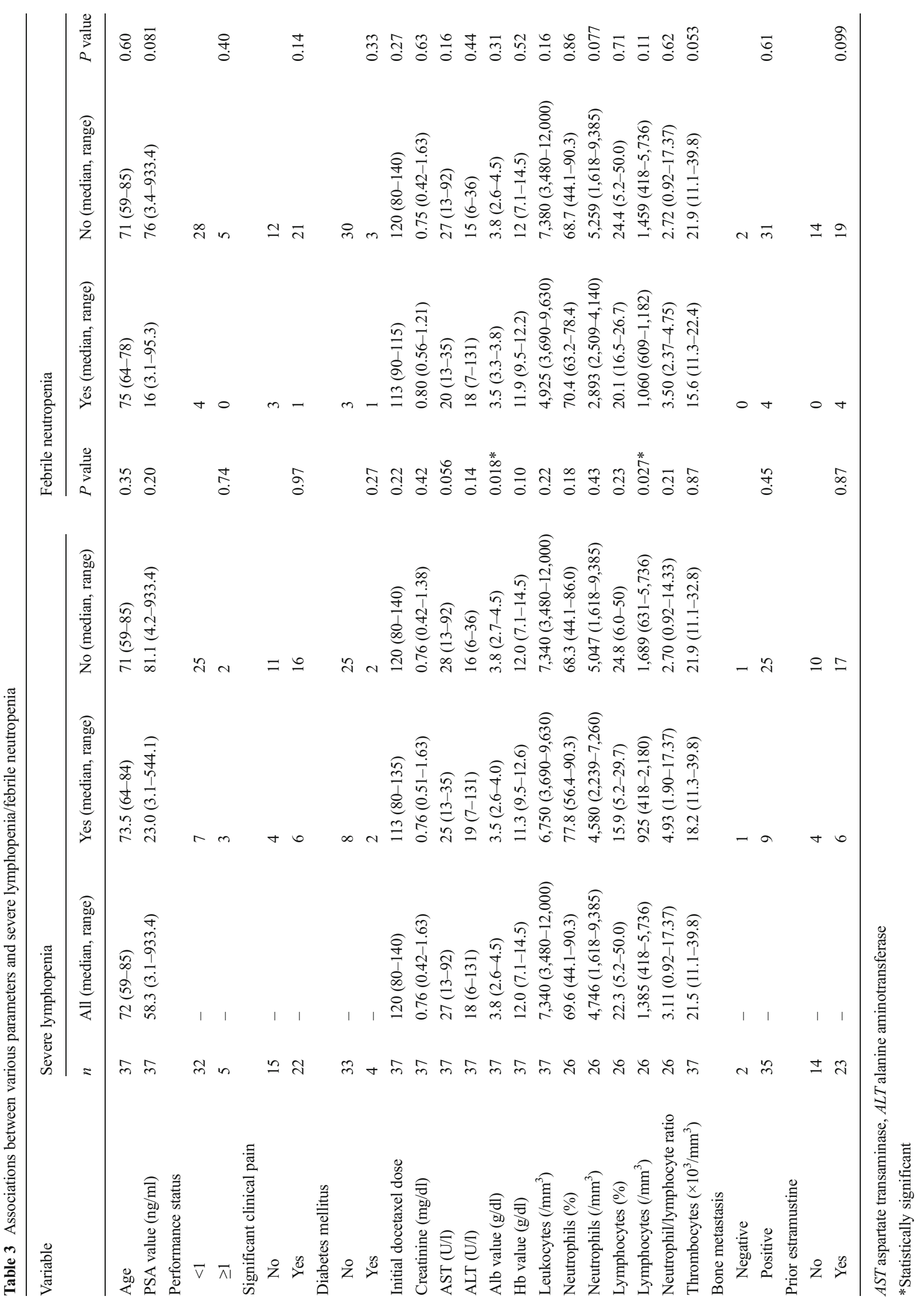


Fig. 1 ROC curves of serum albumin and baseline lymphocyte count for the diagnosis of severe lymphopenia (a and $\mathbf{c}$ ) and FN (b and d), respectively. The curves describe the association between sensitivity and specificity


C

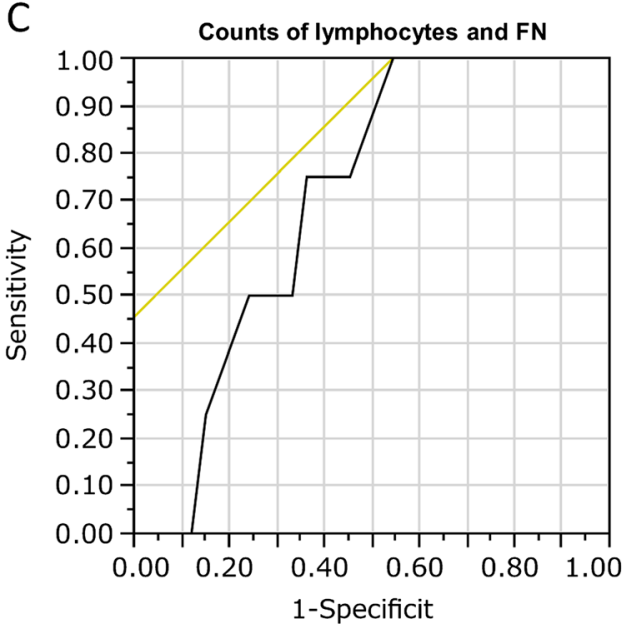

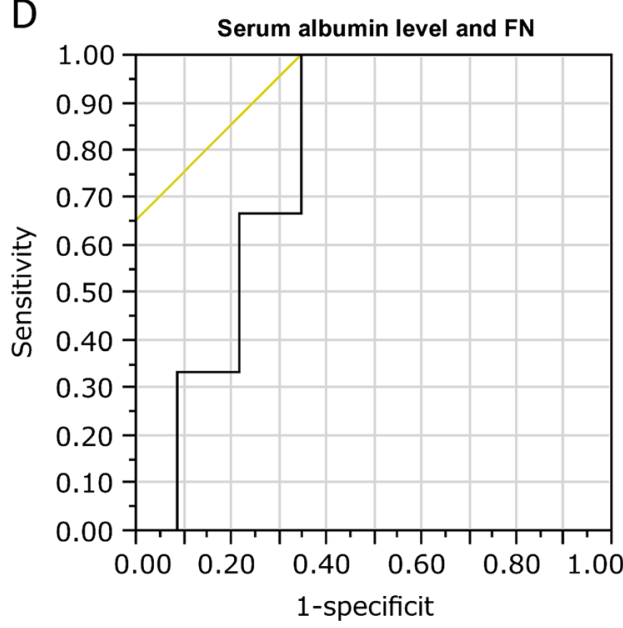

\section{Discussion}

The natural taxane derived from $T$. baccata, docetaxel, inhibits cellular mitosis and exerts anti-cancer effects by promoting tubulin assembly and inhibiting microtubule depolymerization. Two randomized clinical trials in 2004 demonstrated significantly improved survival of patients with CRPC who received docetaxel-based chemotherapy [6,7], and since then, docetaxel has been a standard therapy for CRPC globally. Clinical trials reported incidences of severe AEs, represented by treatmentrelated death, in $0.3 \%$ [6] and $2.4 \%$ [7] of Western patients, and in $0 \%$ in a phase II study conducted in Japan [19], suggesting similarities between Western and Japanese populations. However, the incidences of FN and severe neutropenia ( $\geq$ grade 3 ) were 3 and $32 \%$ among Western populations [6] and 16.3 and $93.0 \%$ among Japanese populations [19], respectively, suggesting a higher incidence of severe hematological AEs in Japanese men. In addition, the rates of FN and severe neutropenia were 10.8 and $97.3 \%$ (Table 1), which are higher than those reported in Western countries [6], but similar to reports from Japan [19]. These discrepancies may be attributable to ethnic differences between Western and Japanese populations. In the current study, however, the rate of severe non-hematological AEs, including treatment-related deaths, was comparable with previous reports, suggesting comparable incidences of non-hematological AEs in Western and Japanese populations.

FN is a common and life-threatening complication of cancer chemotherapy, which can be partially prevented by the exclusion of high-risk patients from such treatments, reduction of chemotherapy dose, or the prophylactic use of G-CSF [17, 20]. Clinical guidelines from the American Society of Clinical Oncology and the National Comprehensive Cancer Network in the USA and from the European Organization for Research and Treatment of Cancer similarly recommend that G-CSF should be administered prophylactically if the risk of $\mathrm{FN}$ is greater than $20 \%[18,24,25]$. In the case of chemotherapeutic regimens with an intermediate risk of FN (10-20\%), the guidelines emphasize the importance of considering the risk factors [18, 24, 25]. Risk factors considered to support the use of G-CSF include age, previous cytotoxic or radiation therapy, preexisting neutropenia, bone marrow involvement, reduced PS, reduced nutritional status, advanced cancer, impaired renal function, hepatic dysfunction, and infection. However, 
estimation of the individual risk for each patient remains unreliable in clinical practice. In addition, few studies have identified the specific risk factors in patients treated with docetaxel chemotherapy for CRPC. Identification of the individual risk factors for $\mathrm{FN}$ is thus an important objective for preventing $\mathrm{FN}$. The results of the present study suggest that severe posttreatment lymphopenia may identify a subgroup of CRPC patients treated with docetaxel who are at high risk for FN. Several previous studies have consistently shown that posttreatment lymphopenia is a predictive factor for FN among adult and pediatric patients treated with several chemotherapy regimens [26-28].

Recently, Lyman et al. established the prediction model of neutropenic complication risk in patients treated with various cancer chemotherapies, reporting that age, prior chemotherapy, renal dysfunction, high bilirubin level, and low leukocyte count were independent risk factor for severe or febrile neutropenia [29]. Along with this notion, this study identified that low lymphocyte count was an independent risk factor for FN. On the other hand, the established risk factors in various types of chemotherapies such as age and advanced disease were not risk factors in this cohort. This inconsistency may derive from a difference in the background and in the type of chemotherapy used.

However, although severe post-treatment lymphopenia has been identified as a risk factor for FN during docetaxel chemotherapy, it cannot be detected before the initiation of chemotherapy, thus delaying essential efforts to avoid FN. Accordingly, we investigated potential pre-treatment risk factors for FN, and identified serum albumin and lymphocyte count as possible risk factors for severe lymphopenia. Baseline lymphocyte count was also consistently reported to be a risk factor for $\mathrm{FN}$ among patients with non-hematological malignancies [30, 31]. Hypoalbuminemia was also identified as a risk factor, consistent with the fact that low serum albumin correlated with a higher incidence of FN among patients with non-Hodgkin lymphoma [32]. Additionally, low serum albumin was also reported to correlate with severe cytotoxicity induced by paclitaxel and cisplatin chemotherapy for nonsmall cell lung cancer [33]. Hypoalbuminemia may thus contribute to lymphopenia, possibly through augmenting negative aspects of chemotherapy. As found in a previous study [34], serum albumin was also identified as a possible prognostic factor for OS among patients treated with docetaxel chemotherapy, though the correlation was not significant. Hypoalbuminemia is therefore both a risk factor for severe AEs, including lymphopenia, and a prognostic factor for poor OS, suggesting that serum albumin is a critical value for predicting both the positive and negative therapeutic aspects of docetaxel chemotherapy. Neutrophil/lymphocyte ratio was also identified as a prognostic factor, with greater significance than serum albumin level. This provides the first evidence for neutrophil/lymphocyte ratio as a prognostic factor among
CRPC patients treated with docetaxel chemotherapy, though higher neutrophil/lymphocyte ratios have been correlated with poor prognosis among patients with hormone-naïve prostate cancer [35], as well as patients with CRPC treated with ketoconazole [36].

The present study had several limitations. First, 18 (48.6\%) patients required dose-reductions of docetaxel because of severe toxicities. Second, this was a retrospective study involving patients treated with different docetaxel regimens by several physicians. Finally, the sample size of 37 patients was small for a common disease such as CRPC.

In conclusion, non-hematological AEs as well as substantial hematological AEs were recognized in the Japanese population treated with docetaxel chemotherapy against CRPC. Taxane-based chemotherapies against CRPC including docetaxel as well as cabazitaxel have been reported to cause critical AEs by sepsis due to neutropenia at a rather low rate $[6,8]$. This study indicated that severe lymphopenia at posttreatment may predict FN, and baseline lymphocyte count and serum albumin were identified as possible risk factors for FN, followed by lymphopenia. Overall, these results suggest that pre- and post-treatment lymphopenia, and pretreatment serum albumin should be taken into account when deciding whether or not to treat CRPC patients with docetaxel chemotherapy, and when considering dosage modifications and the prophylactic application of G-CSF.

Acknowledgments We would like to thank the Edanz Group Japan for the editorial assistance.

Conflict of interest The authors declare no conflicts of interest.

Grant support This work was supported by the Kakenhi grants (24890160 and 25462484) from the Ministry of Education, Culture, Sports, Science and Technology of Japan (MEXT), Japan, and a Research Promotion Grant from the Kanae Foundation for the Promotion of Medical Science (to MS), Japan.

\section{References}

1. Huggins C, Hodges CV (1941) Studies on prostatic cancer. I. The effect of castration, of estrogen and androgen injection on serum phosphatases in metastatic carcinoma of the prostate. Cancer Res 1: 293-297

2. Miyamoto H, Messing EM, Chang C (2004) Androgen deprivation therapy for prostate cancer: current status and future prospects. Prostate 61:332-335

3. Sharifi N, Gulley JL, Dahut WL (2010) An update on androgen deprivation therapy for prostate cancer. Endocr Relat Cancer 17: R305-R315

4. Sadar MD (2011) Small molecule inhibitors targeting the "achilles' heel" of androgen receptor activity. Cancer Res 71:1208-1213

5. Shiota M, Yokomizo A, Naito S (2012) Pro-survival and antiapoptotic properties of androgen receptor signaling by oxidative stress promote treatment resistance in prostate cancer. Endocr Relat Cancer 19:R243-R253 
6. Tannock IF, de Wit R, Berry WR, Horti J, Pluzanska A, Chi KN, Oudard S, Théodore C, James ND, Turesson I, Rosenthal MA, Eisenberger MA, TAX 327 Investigators (2004) Docetaxel plus prednisone or mitoxantrone plus prednisone for advanced prostate cancer. N Engl J Med 351:1502-1512

7. Petrylak DP, Tangen CM, Hussain MH, Lara PN Jr, Jones JA, Taplin ME, Burch PA, Berry D, Moinpour C, Kohli M, Benson MC, Small EJ, Raghavan D, Crawford ED (2004) Docetaxel and estramustine compared with mitoxantrone and prednisone for advanced refractory prostate cancer. N Engl J Med 351:1513-1520

8. de Bono JS, Oudard S, Ozguroglu M, Hansen S, Machiels JP, Kocak I, Gravis G, Bodrogi I, Mackenzie MJ, Shen L, Roessner M, Gupta S, Sartor AO, Investigators TROPIC (2010) Prednisone plus cabazitaxel or mitoxantrone for metastatic castration-resistant prostate cancer progressing after docetaxel treatment: a randomised openlabel trial. Lancet 376:1147-1154

9. de Bono JS, Logothetis CJ, Molina A, Fizazi K, North S, Chu L, Chi KN, Jones RJ, Goodman OB Jr, Saad F, Staffurth JN, Mainwaring P, Harland S, Flaig TW, Hutson TE, Cheng T, Patterson H, Hainsworth JD, Ryan CJ, Sternberg CN, Ellard SL, Fléchon A, Saleh M, Scholz M, Efstathiou E, Zivi A, Bianchini D, Loriot Y, Chieffo N, Kheoh T, Haqq CM, Scher HI, COU-AA-301 Investigators (2011) Abiraterone and increased survival in metastatic prostate cancer. N Engl J Med 364:1995-2005

10. Scher HI, Fizazi K, Saad F, Taplin ME, Sternberg CN, Miller K, de Wit R, Mulders P, Chi KN, Shore ND, Armstrong AJ, Flaig TW, Fléchon A, Mainwaring P, Fleming M, Hainsworth JD, Hirmand M, Selby B, Seely L, de Bono JS, Investigators AFFIRM (2012) Increased survival with enzalutamide in prostate cancer after chemotherapy. N Engl J Med 367:1187-1197

11. Ryan CJ, Smith MR, de Bono JS, Molina A, Logothetis CJ, de Souza P, Fizazi K, Mainwaring P, Piulats JM, Ng S, Carles J, Mulders PF, Basch E, Small EJ, Saad F, Schrijvers D, Van Poppel H, Mukherjee SD, Suttmann H, Gerritsen WR, Flaig TW, George DJ, Yu EY, Efstathiou E, Pantuck A, Winquist E, Higano CS, Taplin ME, Park Y, Kheoh T, Griffin T, Scher HI, Rathkopf DE, COU-AA-302 Investigators (2013) Abiraterone in metastatic prostate cancer without previous chemotherapy. N Engl J Med 368:138-148

12. Kantoff PW, Higano CS, Shore ND, Berger ER, Small EJ, Penson DF, Redfern CH, Ferrari AC, Dreicer R, Sims RB, Xu Y, Frohlich MW, Schellhammer PF, IMPACT Study Investigators (2010) Sipuleucel-T immunotherapy for castration-resistant prostate cancer. N Engl J Med 363:411-422

13. Shiota M, Yokomizo A, Fujimoto N, Kuruma H, Naito S (2013) Castration-resistant prostate cancer: novel therapeutics pre- or posttaxane administration. Curr Cancer Drug Targets 13:444-459

14. Caggiano V, Weiss RV, Rickert TS, Linde-Zwirble WT (2005) Incidence, cost, and mortality of neutropenia hospitalization associated with chemotherapy. Cancer 103:1916-1924

15. Bodey GP, Buckley M, Sathe YS, Freireich EJ (1966) Quantitative relationships between circulating leukocytes and infection in patients with acute leukemia. Ann Intern Med 64:328-340

16. Kuderer NM, Dale DC, Crawford J, Cosler LE, Lyman GH (2006) Mortality, morbidity, and cost associated with febrile neutropenia in adult cancer patients. Cancer 106:2258-2266

17. Bennett CL, Djulbegovic B, Norris LB, Armitage JO (2013) Colonystimulating factors for febrile neutropenia during cancer therapy. $\mathrm{N}$ Engl J Med 368:1131-1139

18. Aapro MS, Bohlius J, Cameron DA, Dal Lago L, Donnelly JP, Kearney N, Lyman GH, Pettengell R, Tjan-Heijnen VC, Walewski J, Weber DC, Zielinski C, European Organisation for Research and Treatment of Cancer (2011) 2010 update of EORTC guidelines for the use of granulocyte-colony stimulating factor to reduce the incidence of chemotherapy-induced febrile neutropenia in adult patients with lymphoproliferative disorders and solid tumours. Eur J Cancer 47:8-32
19. Naito S, Tsukamoto T, Koga H, Harabayashi T, Sumiyoshi Y, Hoshi S, Akaza H (2008) Docetaxel plus prednisolone for the treatment of metastatic hormone-refractory prostate cancer: a multicenter Phase II trial in Japan. Jpn J Clin Oncol 38:365-372

20. Cooper KL, Madan J, Whyte S, Stevenson MD, Akehurst RL (2011) Granulocyte colony-stimulating factors for febrile neutropenia prophylaxis following chemotherapy: systematic review and metaanalysis. BMC Cancer 11:404

21. Scher HI, Halabi S, Tannock I, Morris M, Sternberg CN, Carducci MA, Eisenberger MA, Higano C, Bubley GJ, Dreicer R, Petrylak D, Kantoff P, Basch E, Kelly WK, Figg WD, Small EJ, Beer TM, Wilding G, Martin A, Hussain M, Prostate Cancer Clinical Trials Working Group (2008) Design and end points of clinical trials for patients with progressive prostate cancer and castrate levels of testosterone: recommendations of the Prostate Cancer Clinical Trials Working Group. J Clin Oncol 26:1148-1159

22. National Cancer Institute. (http://www.cancer.gov/).

23. Armstrong AJ, Tannock IF, de Wit R, George DJ, Eisenberger M, Halabi S (2010) The development of risk groups in men with metastatic castration-resistant prostate cancer based on risk factors for PSA decline and survival. Eur J Cancer 46:517-525

24. Smith TJ, Khatcheressian J, Lyman GH, Ozer H, Armitage JO, Balducci L, Bennett CL, Cantor SB, Crawford J, Cross SJ, Demetri G, Desch CE, Pizzo PA, Schiffer CA, Schwartzberg L, Somerfield MR, Somlo G, Wade JC, Wade JL, Winn RJ, Wozniak AJ, Wolff AC (2006) 2006 update of recommendations for the use of white blood cell growth factors: an evidence-based clinical practice guideline. J Clin Oncol 24:3187-3205

25. National Comprehensive Cancer Network. Myeloid growth factors v1020012 (http://www.nccn.org).

26. Ray-Coquard I, Borg C, Bachelot T, Sebban C, Philip I, Clapisson G, Le Cesne A, Biron P, Chauvin F, Blay JY, ELYPSE study group (2003) Baseline and early lymphopenia predict for the risk of febrile neutropenia after chemotherapy. Br J Cancer 88:181-186

27. Choi CW, Sung HJ, Park KH, Yoon SY, Kim SJ, Oh SC, Seo JH, Kim BS, Shin SW, Kim YH, Kim JS (2003) Early lymphopenia as a risk factor for chemotherapy-induced febrile neutropenia. Am J Hematol 73:263-266

28. Oguz A, Karadeniz C, Ckitak EC, Cil V (2006) Which one is a risk factor for chemotherapy-induced febrile neutropenia in childhood solid tumors: early lymphopenia or monocytopenia? Pediatr Hematol Oncol 23:143-151

29. Lyman GH, Kuderer NM, Crawford J, Wolff DA, Culakova E, Poniewierski MS, Dale DC (2011) Predicting individual risk of neutropenic complications in patients receiving cancer chemotherapy. Cancer 117:1917-1927

30. Jenkins P, Freeman S (2009) Pretreatment haematological laboratory values predict for excessive myelosuppression in patients receiving adjuvant FEC chemotherapy for breast cancer. Ann Oncol 20:34-40

31. Jenkins P, Scaife J, Freeman S (2012) Validation of a predictive model that identifies patients at high risk of developing febrile neutropaenia following chemotherapy for breast cancer. Ann Oncol 23:1766-1771

32. Pettengell R, Bosly A, Szucs TD, Jackisch C, Leonard R, Paridaens $\mathrm{R}$, Constenla M, Schwenkglenks M, Impact of Neutropenia in Chemotherapy-European Study Group (INC-EU) (2009) Multivariate analysis of febrile neutropenia occurrence in patients with non-Hodgkin lymphoma: data from the INC-EU Prospective Observational European Neutropenia Study. Br J Haematol 144:677685

33. Arrieta O, Michel Ortega RM, Villanueva-Rodríguez G, SernaThomé MG, Flores-Estrada D, Diaz-Romero C, Rodríguez CM, Martínez L, Sánchez-Lara K (2010) Association of nutritional status and serum albumin levels with development of toxicity in patients with advanced non-small cell lung cancer treated with paclitaxelcisplatin chemotherapy: a prospective study. BMC Cancer 10:50 
34. Linton A, Pond G, Clarke S, Vardy J, Galsky M, Sonpavde G (2013) Glasgow prognostic score as a prognostic factor in metastatic castration-resistant prostate cancer treated with docetaxel-based chemotherapy. Clin Genitourin Cancer 11: 423-430

35. Shafique K, Proctor MJ, McMillan DC, Qureshi K, Leung H, Morrison DS (2012) Systemic inflammation and survival of patients with prostate cancer: evidence from the Glasgow
Inflammation Outcome Study. Prostate Cancer Prostatic Dis 15: 195-201

36. Keizman D, Gottfried M, Ish-Shalom M, Maimon N, Peer A, Neumann A, Rosenbaum E, Kovel S, Pili R, Sinibaldi V, Carducci MA, Hammers H, Eisenberger MA, Sella A (2012) Pretreatment neutrophil-to-lymphocyte ratio in metastatic castration-resistant prostate cancer patients treated with ketoconazole: association with outcome and predictive nomogram. Oncologist 17:1508-1514 